\title{
11. PERINATAL DEATHS
}

\section{REVIEW OF PERINATAL DEATHS 2003}

\section{Introduction}

This chapter presents the results of perinatal death reviews carried out by the NSW Maternal and Perinatal Committee, which is a quality assurance committee established under the Health Administration Act 1982. The Committee is privileged under the Act to carry out confidential reviews of maternal and perinatal deaths.

NSW Department of Health Circular No. 2002/6 describes hospital procedures for review and reporting of perinatal deaths. The circular is available on the Department's web site at: www.health.nsw.gov.au/fcsd/rmc/cib/circulars/ 2002/cir2002-6.pdf. The Maternal and Perinatal Committee carries out reviews of perinatal deaths occurring among fetuses or infants of at least 22 weeks gestation or at least 500 grams birthweight. The criteria used by the NSW Midwives Data Collection (MDC) for reporting of births is at least 400 grams birthweight or at least 20 weeks gestation. The Maternal and Perinatal Committee reviews deaths that have a slightly higher threshold to focus attention on deaths that are more likely to be preventable.

Perinatal deaths were reviewed by the Committee's Perinatal Outcomes Working Party. Both stillbirths and neonatal deaths were classified according to an obstetric cause-specific classification, the Perinatal Society of Australia and New Zealand Perinatal Death Classification (PSANZ-PDC). Neonatal deaths were also classified by neonatal cause according to the Perinatal Society of Australia and New Zealand Neonatal Death Classification (PSANZ-NDC).

Of the 619 perinatal deaths of at least 22 weeks gestation or at least 500 grams birthweight reported to the NSW Midwives Data Collection in 2003, confidential reports on 595 (96.1 per cent) were reviewed and classified. Of the 429 stillbirths reported to the MDC, reviews were carried out on 403 (93.9 per cent). The MDC was notified of 190 neonatal deaths. However, reviews were carried out on 192 neonatal deaths, reflecting under-enumeration of neonatal deaths on the MDC. Comparative information is also presented for 2001 and 2002.

\section{Trends in obstetric antecedents of perinatal death}

Between 2001 and 2003, the pattern of antecedent causes of death remained fairly stable (Figure 18, Table 125). About 30 per cent of perinatal deaths were unexplained. The next most common obstetric antecedents were fetal abnormalities followed by spontaneous preterm birth, specific perinatal conditions (such as twin-to-twin transfusion) and antepartum haemorrhage.

\section{Obstetric antecedents of perinatal death 2003}

\section{Congenital abnormality}

Congenital abnormalities were the underlying cause for 95 deaths (Table 126). Chromosomal abnormalities were most common ( $n=27,28.4$ per cent). Of these, 6 were trisomy 21,10 were trisomy 18,5 were trisomy 13,1 was Turner syndrome, and 5 were other abnormalities.

Twenty-two deaths were associated with abnormalities of the central nervous system (23.2 per cent), of which 10 were congenital hydrocephalus and 6 were neural tube defects. Sixteen deaths occurred among babies who had multiple abnormalities not associated with a chromosomal abnormality.

Fifteen deaths were associated with abnormalities of the cardiovascular system, of which 7 were cases of hypoplastic left heart syndrome. Three deaths were associated with congenital diaphragmatic hernia.

\section{Perinatal infection}

Thirty deaths were found to be due to infection, of which 16 were stillbirths and 14 were neonatal deaths. In 25 deaths there was an associated chorioamnionitis.

The most common infective organism identified was group B streptococcus, which was considered responsible for 4 neonatal deaths and 4 stillbirths. Three neonatal deaths were caused by $E$. Coli infection. There was one neonatal death from a congenital Strep. Pneumoniae infection and another from Staph. Epidermidis infection. One neonatal death followed cytomegalovirus infection. The causative organism was not specified for 16 deaths.

\section{Hypertension}

Thirty-two (5.4 per cent) deaths were considered to be due to maternal hypertension. There were 23 stillbirths and 9 neonatal deaths. The majority ( $n=19,59.4$ per cent) occurred in mothers with pre-eclampsia, two of whom had HELLP syndrome. Two deaths were among babies of twin pregnancies. Five deaths in this group were associated with placental abruption, and one was associated with maternal diabetes.

\section{Antepartum haemorrhage}

Forty-four deaths were due to antepartum haemorrhage, of which 28 were due to placental abruption, 4 were due to placenta praevia, and 3 due to vasa praevia. There were 31 stillbirths, of whom 10 died during labour, and 9 were neonatal deaths. Two cases of placental abruption were associated with a twin pregnancy. Three cases were associated with maternal hypertension. 
FIGURE 18

PERINATAL DEATHS BY OBSTETRIC ANTECEDENT AND YEAR, NSW 2001-2003

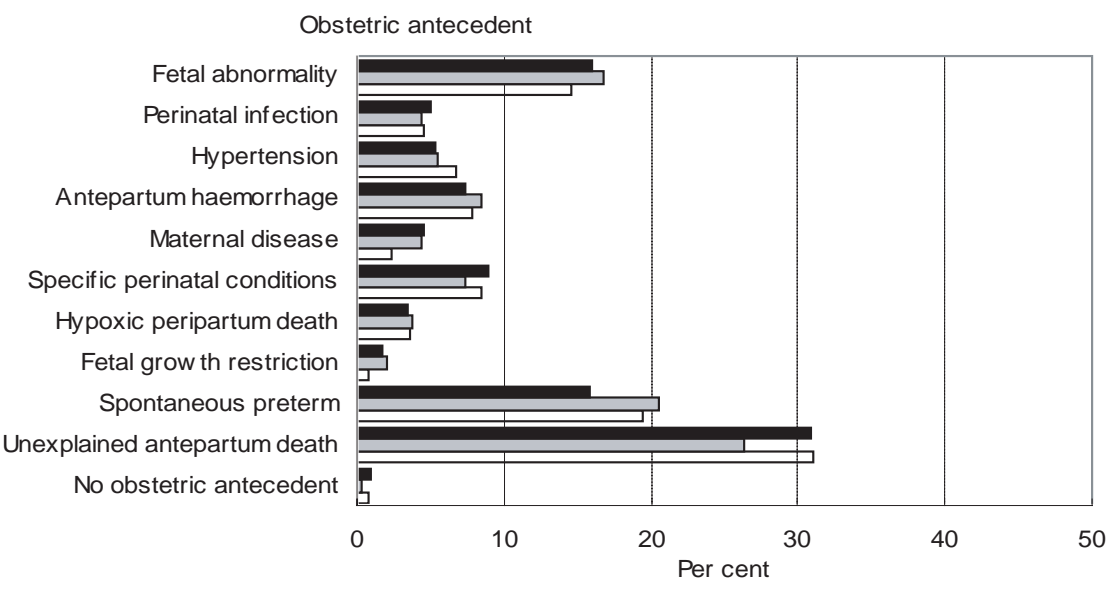

$\square 2001 \square 2002$ घ 2003

Source: NSW Maternal and Perinatal Committee, NSW Department of Health

\section{TABLE 125}

PERINATAL DEATHS BY OBSTETRIC ANTECEDENT AND YEAR, NSW 2001-2003

\begin{tabular}{|c|c|c|c|c|c|c|}
\hline \multirow[t]{2}{*}{ Obstetric antecedent } & \multicolumn{4}{|c|}{$\begin{array}{l}\text { Year } \\
2002\end{array}$} & \multicolumn{2}{|c|}{2003} \\
\hline & No. & $\%$ & No. & $\%$ & No. & $\%$ \\
\hline 1. Fetal abnormality & 90 & 14.6 & 103 & 16.8 & 95 & 16.0 \\
\hline 2. Perinatal infection & 28 & 4.5 & 27 & 4.4 & 30 & 5.0 \\
\hline 3. Hypertension & 41 & 6.7 & 34 & 5.5 & 32 & 5.4 \\
\hline 4. Antepartum haemorrhage & 48 & 7.8 & 52 & 8.5 & 44 & 7.4 \\
\hline 5. Maternal disease & 14 & 2.3 & 27 & 4.4 & 28 & 4.7 \\
\hline 6. Specific perinatal conditions & 52 & 8.4 & 45 & 7.3 & 51 & 8.6 \\
\hline 7. Hypoxic peripartum death & 22 & 3.6 & 23 & 3.8 & 21 & 3.5 \\
\hline 8. Fetal growth restriction & 5 & 0.8 & 13 & 2.1 & 10 & 1.7 \\
\hline 9. Spontaneous preterm & 120 & 19.5 & 126 & 20.6 & 94 & 15.8 \\
\hline 10. Unexplained antepartum death & 191 & 31.0 & 161 & 26.3 & 184 & 30.9 \\
\hline 11. No obstetric antecedent & 5 & 0.8 & 2 & 0.3 & 6 & 1.0 \\
\hline TOTAL & 616 & 100.0 & 613 & 100.0 & 595 & 100.0 \\
\hline
\end{tabular}

Source: NSW Maternal and Perinatal Committee, NSW Department of Health. 
TABLE 126

PERINATAL DEATHS BY OBSTETRIC ANTECEDENT AND PERINATAL OUTCOME, NSW 2003

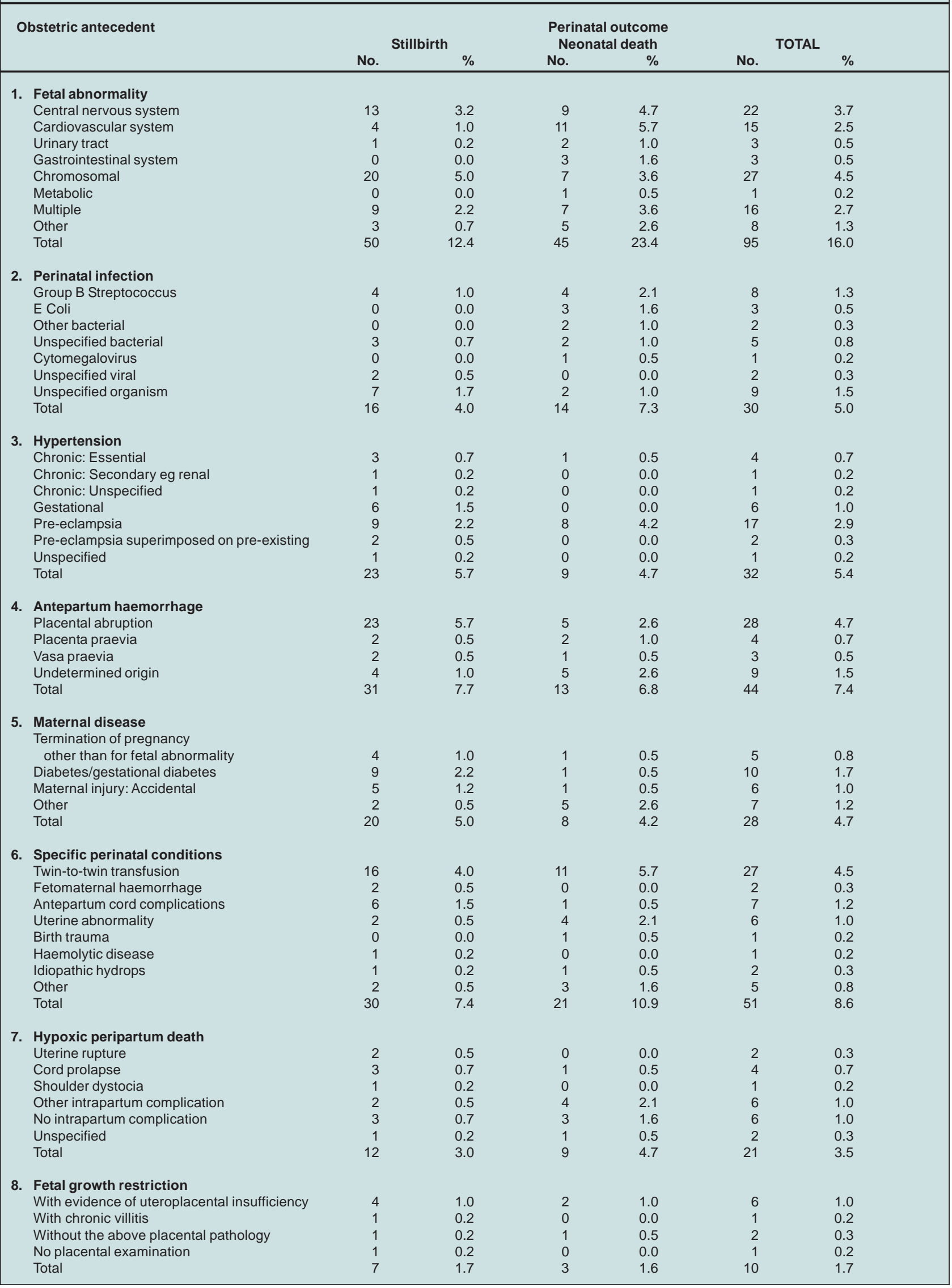


TABLE 126 (continued)

PERINATAL DEATHS BY OBSTETRIC ANTECEDENT AND PERINATAL OUTCOME, NSW 2003

\begin{tabular}{|c|c|c|c|c|c|c|}
\hline \multirow[t]{2}{*}{ Obstetric antecedent } & \multicolumn{2}{|c|}{ Stillbirth } & \multicolumn{2}{|c|}{$\begin{array}{l}\text { Perinatal outcome } \\
\text { Neonatal death }\end{array}$} & \multicolumn{2}{|c|}{ TOTAL } \\
\hline & No. & $\%$ & No. & $\%$ & No. & $\%$ \\
\hline \multirow{2}{*}{\multicolumn{7}{|c|}{$\begin{array}{l}\text { 9. Spontaneous preterm } \\
\text { Intact membranes or membrane rupture }\end{array}$}} \\
\hline & & & & & & \\
\hline with chorioamnionitis & 11 & 2.7 & 25 & 13.0 & 36 & 6.1 \\
\hline without chorioamnionitis & 4 & 1.0 & 12 & 6.3 & 16 & 2.7 \\
\hline no placental examination & 0 & 0.0 & 2 & 1.0 & 2 & 0.3 \\
\hline \multicolumn{7}{|l|}{ Membrane rupture 24 hours or more: } \\
\hline with chorioamnionitis & 9 & 2.2 & 17 & 8.9 & 26 & 4.4 \\
\hline without chorioamnionitis & 1 & 0.2 & 1 & 0.5 & 2 & 0.3 \\
\hline no placental examination & 3 & 0.7 & 4 & 2.1 & 7 & 1.2 \\
\hline \multicolumn{7}{|l|}{ Membrane rupture unknown duration: } \\
\hline with chorioamnionitis & 1 & 0.2 & 1 & 0.5 & 2 & 0.3 \\
\hline without chorioamnionitis & 1 & 0.2 & 1 & 0.5 & 2 & 0.3 \\
\hline unspecified placental examination & 0 & 0.0 & 1 & 0.5 & 1 & 0.2 \\
\hline Total & 30 & 7.4 & 64 & 33.3 & 94 & 15.8 \\
\hline \multicolumn{7}{|l|}{ 10. Unexplained antepartum death } \\
\hline With evidence of uteroplacental insufficiency & 43 & 10.7 & 0 & 0.0 & 43 & 7.2 \\
\hline With chronic villitis & 2 & 0.5 & 0 & 0.0 & 2 & 0.3 \\
\hline Without the above placental pathology & 108 & 26.8 & 0 & 0.0 & 108 & 18.2 \\
\hline No placental examination & 28 & 6.9 & 0 & 0.0 & 28 & 4.7 \\
\hline Unspecified placental examination & 3 & 0.7 & 0 & 0.0 & 3 & 0.5 \\
\hline Total & 184 & 45.7 & 0 & 0.0 & 184 & 30.9 \\
\hline \multicolumn{7}{|l|}{ 11. No obstetric antecedent } \\
\hline Other & 0 & 0.0 & 2 & 1.0 & 2 & 0.3 \\
\hline Unknown/unexplained & 0 & 0.0 & 4 & 2.1 & 4 & 0.7 \\
\hline Total & 0 & 0.0 & 6 & 3.1 & 6 & 1.0 \\
\hline TOTAL & 403 & 100.0 & 192 & 100.0 & 595 & 100.0 \\
\hline
\end{tabular}

Source: NSW Maternal and Perinatal Committee, NSW Department of Health.

\section{Maternal disease}

Twenty-eight deaths were attributed to other maternal conditions including: diabetes (10), motor vehicle accident injury (4), other maternal injury (2), termination of pregnancy (5), antiphospholipid syndrome (1), renal failure (1), thrombocytopaenia (1), and maternal pelvic thrombophlebitis (1).

\section{Specific perinatal conditions}

Of the 51 deaths in this group, twin-twin transfusion accounted for 27 deaths, followed by antepartum cord complications (7) and uterine abormalities (6). Other causes were: prolonged premature rupture of membranes (4), fetomaternal haemorrhage (2), idiopathic hydrops (2), birth trauma (1), haemolytic disease (1), and chorangioma of the placenta (1).

\section{Hypoxic peripartum death}

There were 21 deaths associated with peripartum hypoxia. Two deaths followed uterine rupture- 1 prior to the onset of labour and 1 during labour. Four deaths followed cord prolapse and 1 death followed shoulder dystocia.

Four deaths occurred before the onset of labour, 7 during labour and 1 at an unspecified time prior to birth. The remaining 9 deaths occurred in the neonatal period.

\section{Fetal growth restriction}

In 10 cases, the main obstetric cause of death was considered to be fetal growth restriction (FGR). Of these, 7 were stillbirths and 3 were neonatal deaths. FGR is defined as less than the tenth percentile of birthweight for gestational age with no major congenital abnormalities. If a maternal or fetal cause of FGR was known then the cause of death was classified to the underlying cause of the FGR. Stillbirths with evidence of maceration were not classified as FGR unless there was evidence of growth restriction on serial ultrasound during pregnancy.

\section{Spontaneous preterm}

There were 94 perinatal deaths associated with spontaneous preterm birth, which comprises normally formed babies born before 37 weeks gestation. Of these, 30 (31.9 per cent) were stillbirths and 64 (68.1 per cent) were neonatal deaths. Twenty-nine deaths (30.9 per cent) were at 2122 weeks gestation, 48 (51.1 per cent) were at 23-25 weeks gestation, and 17 (18.1 per cent) occurred between 26 and 36 weeks gestation. Chorioamnionitis was reported in 64 deaths (68.1 per cent). Thirty-five deaths (37.2 per cent) were associated with membrane rupture of 24 hours or more. 


\section{Unexplained antepartum death}

Of the 184 unexplained stillbirths 110 (59.8 per cent) were low birthweight babies and 110 were premature. A variety of associated maternal conditions were reported in this group including: multiple pregnancy (12 deaths), maternal hypertension (8), diabetes (3), epilepsy (2), asthma (1), systemic lupus erythematosis (1) and taking methadone (1). Placental histopathology results were provided for 156 unexplained antepartum deaths ( 84.8 per cent) and evidence of uteroplacental insufficiency was found in 43.

\section{No obstetric antecedent}

Six neonatal deaths were considered not to have an obstetric antecedent. One baby had fetal akinesia syndrome and 1 had primary persistent pulmonary hypertension. No cause of death could be identified for 4 babies-post-mortem and placental histopathology examination had been carried out in 2 cases.

\section{Obstetric cause of perinatal death by hospital service level 2003}

Obstetric service levels are described in the Explanatory Notes of the Methods section (page 16). The majority of perinatal deaths occurred in level 6 hospitals (47.0 per cent, Table 127). The proportion of unexplained intrauterine deaths was substantially lower in level 6 hospitals than other hospitals, possibly due to better access to perinatal post-mortem services. The proportion of deaths associated with congenital abnormalities was highest in level 6 hospitals, reflecting patterns of referral for diagnosis and treatment.

\section{Time of death 2003}

Of the 595 perinatal deaths in 2003, 277 (46.6 per cent) occurred before the onset of labour, 46 (7.7 per cent) occured during labour, 80 (13.4 per cent) occurred at an unknown time before birth, and 192 (32.3 per cent) were neonatal deaths.

\section{Trends in neonatal causes of death}

Bewteen 2001 and 2003 extreme prematurity was the most common cause of neonatal death, accounting for over 40 per cent of all neonatal deaths in 2003 (Table 128). Congenital abnormalities were the next most common cause of neonatal death for the 3 years. There were slightly more deaths attributed to neurological conditions in 2002 and 2003 compared with 2001, particularly hypoxic ischaemic encephalopathy.

\section{Neonatal causes of death 2003}

Of the 192 neonatal deaths reviewed for 2003, 153 (79.7 per cent) were less than 37 weeks gestation (Table 129). The most common neonatal cause of death was extreme prematurity ( $n=86,44.8$ per cent). Thirty-seven infants died from a congenital abnormality. There were 13 deaths due to hypoxic ischaemic encephalopathy and 10 deaths due to intracranial haemorrhage.

\section{Perinatal deaths associated with maternal drug dependency/abuse 2003}

No perinatal deaths were directly attributed to maternal drug dependency or drug abuse. One death occurred in a mother who had a history of drug abuse, but drug use was not considered to be the main cause of death. Two further perinatal deaths were reported among babies of mothers who were participating in a methadone program.

\section{Post-mortem examination 2003}

Postmortem examination is valuable in ascertaining or confirming the cause of death, identifying additional factors which may have contributed to the death, and counselling parents about the cause of death. Postmortem examinations were carried out for 193 (32.4 per cent) deaths: 161 stillborn infants (40.0 per cent) and 32 neonatal deaths (16.7 per cent). Placental histopathology was carried out in 484 perinatal deaths (81.3 per cent).

\section{TABLE 127}

PERINATAL DEATHS BY OBSTETRIC ANTECEDENT AND HOSPITAL SERVICE LEVEL, NSW 2003

\begin{tabular}{|c|c|c|c|c|c|c|c|c|c|c|c|c|c|c|}
\hline \multirow[t]{3}{*}{ Obstetric antecedent } & \multicolumn{14}{|c|}{ Hospital service level } \\
\hline & \multicolumn{2}{|c|}{ Level 2} & \multicolumn{2}{|c|}{ Level 3} & \multicolumn{2}{|c|}{$\begin{array}{l}\text { Hospltal } \\
\text { Level } 4\end{array}$} & \multicolumn{2}{|c|}{ Level 5} & \multicolumn{2}{|c|}{ Level 6} & \multicolumn{2}{|c|}{ Private } & \multicolumn{2}{|c|}{ TOTAL } \\
\hline & No. & $\%$ & No. & $\%$ & No. & $\%$ & No. & $\%$ & No. & $\%$ & No. & $\%$ & No. & $\%$ \\
\hline 1. Fetal abnormality & 0 & 0.0 & 3 & 7.7 & 19 & 16.4 & 12 & 16.2 & 43 & 15.9 & 6 & 8.7 & 83 & 14.4 \\
\hline 2. Perinatal infection & 0 & 0.0 & 2 & 5.1 & 2 & 1.7 & 3 & 4.1 & 22 & 8.1 & 1 & 1.4 & 30 & 5.2 \\
\hline 3. Hypertension & 0 & 0.0 & 2 & 5.1 & 4 & 3.4 & 3 & 4.1 & 19 & 7.0 & 2 & 2.9 & 30 & 5.2 \\
\hline 4. Antepartum haemorrhage & 0 & 0.0 & 6 & 15.4 & 9 & 7.8 & 8 & 10.8 & 17 & 6.3 & 4 & 5.8 & 44 & 7.7 \\
\hline 5. Maternal disease\# & 0 & 0.0 & 2 & 5.1 & 6 & 5.2 & 3 & 4.1 & 12 & 4.4 & 4 & 5.8 & 28 & 4.9 \\
\hline 6. Specific perinatal conditions & 0 & 0.0 & 2 & 5.1 & 8 & 6.9 & 5 & 6.8 & 29 & 10.7 & 7 & 10.1 & 51 & 8.9 \\
\hline 8. Hypoxic peripartum death & 1 & 16.7 & 6 & 15.4 & 4 & 3.4 & 0 & 0.0 & 6 & 2.2 & 2 & 2.9 & 19 & 3.3 \\
\hline 9. Fetal growth restriction & 0 & 0.0 & 1 & 2.6 & 2 & 1.7 & 0 & 0.0 & 7 & 2.6 & $\overline{0}$ & 0.0 & 10 & 1.7 \\
\hline 10. Spontaneous preterm & 2 & 33.3 & 5 & 12.8 & 14 & 12.1 & 5 & 6.8 & 54 & 20.0 & 11 & 15.9 & 91 & 15.8 \\
\hline 11. Unexplained antepartum death & 3 & 50.0 & 10 & 25.6 & 46 & 39.7 & 34 & 45.9 & 59 & 21.9 & 32 & 46.4 & 184 & 32.0 \\
\hline 12. No obstetric antecedent & 0 & 0.0 & 0 & 0.0 & 2 & 1.7 & 1 & 1.4 & 2 & 0.7 & 0 & 0.0 & 5 & 0.9 \\
\hline TOTAL & 6 & 100.0 & 39 & 100.0 & 116 & 100.0 & 74 & 100.0 & 270 & 100.0 & 69 & 100.0 & 575 & 100.0 \\
\hline
\end{tabular}


TABLE 128

NEONATAL DEATHS BY CAUSE AND YEAR, NSW 2001-2003

\begin{tabular}{|c|c|c|c|c|c|c|}
\hline \multirow{3}{*}{ Neonatal cause } & \multicolumn{6}{|c|}{ Year } \\
\hline & \multicolumn{2}{|c|}{2001} & \multicolumn{2}{|c|}{2002} & \multicolumn{2}{|c|}{2003} \\
\hline & No. & $\%$ & No. & $\%$ & No. & $\%$ \\
\hline \multicolumn{7}{|l|}{ 1. Congenital abnormality } \\
\hline Central nervous system & 6 & 3.2 & 6 & 3.0 & 9 & 4.7 \\
\hline Cardiovascular system & 8 & 4.2 & 2 & 1.0 & 11 & 5.7 \\
\hline Urinary tract & 5 & 2.6 & 2 & 1.0 & 3 & 1.6 \\
\hline Gastrointestinal tract & 2 & 1.1 & 2 & 1.0 & 2 & 1.0 \\
\hline Chromosomal & 3 & 1.6 & 8 & 4.0 & 3 & 1.6 \\
\hline Metabolic & 0 & 0.0 & 1 & 0.5 & 0 & 0.0 \\
\hline Multiple & 5 & 2.6 & 5 & 2.5 & 2 & 1.0 \\
\hline Unspecified & 0 & 0.0 & 1 & 0.5 & 0 & 0.0 \\
\hline Other & 14 & 7.4 & 12 & 5.9 & 7 & 3.6 \\
\hline Total & 43 & 22.8 & 39 & 19.3 & 37 & 19.3 \\
\hline \multicolumn{7}{|l|}{ 2. Extreme prematurity } \\
\hline Not resuscitated & 34 & 18.0 & 39 & 19.3 & 45 & 23.4 \\
\hline Unsuccessful resuscitation & 34 & 18.0 & 31 & 15.3 & 22 & 11.5 \\
\hline Resuscitation unspecified or unknown & 16 & 8.5 & 10 & 5.0 & 19 & 9.9 \\
\hline Total & 84 & 44.4 & 80 & 39.6 & 86 & 44.8 \\
\hline \multicolumn{7}{|l|}{ 3. Cardio-respiratory disorders } \\
\hline Respiratory distress syndrome & 8 & 4.2 & 5 & 2.5 & 6 & 3.1 \\
\hline Meconium aspiration syndrome & 1 & 0.5 & 1 & 0.5 & 1 & 0.5 \\
\hline Primary persistent pulmonary hypertension & 2 & 1.1 & 2 & 1.0 & 1 & 0.5 \\
\hline Pulmonary hypoplasia & 6 & 3.2 & 8 & 4.0 & 5 & 2.6 \\
\hline Chronic neonatal lung disease & 0 & 0.0 & 0 & 0.0 & 2 & 1.0 \\
\hline Other & 6 & 3.2 & 8 & 4.0 & 6 & 3.1 \\
\hline Total & 23 & 12.2 & 24 & 11.9 & 21 & 10.9 \\
\hline \multicolumn{7}{|l|}{ 4. Infection } \\
\hline Congenital bacterial & 2 & 1.1 & 7 & 3.5 & 3 & 1.6 \\
\hline Acquired bacterial & 4 & 2.1 & 8 & 4.0 & 6 & 3.1 \\
\hline Fungal & 0 & 0.0 & 1 & 0.5 & 1 & 0.5 \\
\hline Unspecified organism & 2 & 1.1 & 0 & 0.0 & 0 & 0.0 \\
\hline Other & 0 & 0.0 & 1 & 0.5 & 1 & 0.5 \\
\hline Total & 8 & 4.2 & 17 & 8.4 & 11 & 5.7 \\
\hline \multicolumn{7}{|l|}{ 5. Neurological } \\
\hline Hypoxic ischaemic encephalopathy / & & & & & & \\
\hline perinatal asphyxia & 8 & 4.2 & 16 & 7.9 & 13 & 6.8 \\
\hline Intracranial haemorrhage & 10 & 5.3 & 11 & 5.4 & 10 & 5.2 \\
\hline Other & 0 & 0.0 & 0 & 0.0 & 1 & 0.5 \\
\hline Total & 18 & 9.5 & 27 & 13.4 & 24 & 12.5 \\
\hline \multicolumn{7}{|l|}{ 6. Gastrointestinal } \\
\hline Necrotising enterocolitis & 2 & 1.1 & 5 & 2.5 & 5 & 2.6 \\
\hline Other & 1 & 0.5 & 1 & 0.5 & 1 & 0.5 \\
\hline Total & 3 & 1.6 & 6 & 3.0 & 6 & 3.1 \\
\hline \multicolumn{7}{|l|}{ 7. Other } \\
\hline SIDS & 0 & 0.0 & 0 & 0.0 & 1 & 0.5 \\
\hline Trauma & 0 & 0.0 & 1 & 0.5 & 0 & 0.0 \\
\hline Other & 7 & 3.7 & 3 & 1.5 & 5 & 2.6 \\
\hline Undetermined / not stated & 3 & 1.6 & 5 & 2.5 & 1 & 0.5 \\
\hline Total & 10 & 5.3 & 9 & 4.5 & 7 & 3.6 \\
\hline TOTAL & 189 & 100.0 & 202 & 100.0 & 192 & 100.0 \\
\hline
\end{tabular}

Source: NSW Maternal and Perinatal Committee, NSW Department of Health. 


\section{TABLE 129}

NEONATAL DEATHS BY CAUSE AND GESTATIONAL AGE, NSW 2003

\begin{tabular}{|c|c|c|c|c|c|c|}
\hline \multirow{3}{*}{ Neonatal cause } & \multicolumn{6}{|c|}{ Gestational age (weeks) } \\
\hline & \multicolumn{2}{|c|}{ Less than 37} & \multicolumn{2}{|c|}{$37+$} & \multicolumn{2}{|c|}{ TOTAL } \\
\hline & No. & $\%$ & No. & $\%$ & No. & $\%$ \\
\hline \multicolumn{7}{|l|}{ 1. Congenital abnormality } \\
\hline Central nervous system & 5 & 3.3 & 4 & 10.3 & 9 & 4.7 \\
\hline Cardiovascular system & 6 & 3.9 & 5 & 12.8 & 11 & 5.7 \\
\hline Urinary tract & 2 & 1.3 & 1 & 2.6 & 3 & 1.6 \\
\hline Gastrointestinal tract & 2 & 1.3 & 0 & 0.0 & 2 & 1.0 \\
\hline Chromosomal & 2 & 1.3 & 1 & 2.6 & 3 & 1.6 \\
\hline Multiple & 2 & 1.3 & 0 & 0.0 & 2 & 1.0 \\
\hline Other & 4 & 2.6 & 3 & 7.7 & 7 & 3.6 \\
\hline Total & 23 & 15.0 & 14 & 35.9 & 37 & 19.3 \\
\hline \multicolumn{7}{|l|}{ 2. Extreme prematurity } \\
\hline Not resuscitated & 45 & 29.4 & 0 & 0.0 & 45 & 23.4 \\
\hline Unsuccessful resuscitation & 22 & 14.4 & 0 & 0.0 & 22 & 11.5 \\
\hline Resuscitation unspecified or unknown & 19 & 12.4 & 0 & 0.0 & 19 & 9.9 \\
\hline Total & 86 & 56.2 & 0 & 0.0 & 86 & 44.8 \\
\hline \multicolumn{7}{|l|}{ 3. Cardio-respiratory disorders } \\
\hline Other & 4 & 2.6 & 2 & 5.1 & 6 & 3.1 \\
\hline Hyaline membrane disease- & & & & & & \\
\hline Respiratory distress syndrome & 6 & 3.9 & 0 & 0.0 & 6 & 3.1 \\
\hline Meconium aspiration syndrome & 0 & 0.0 & 1 & 2.6 & 1 & 0.5 \\
\hline Primary persistent pulmonary hypertension & 0 & 0.0 & 1 & 2.6 & 1 & 0.5 \\
\hline Pulmonary hypoplasia & 4 & 2.6 & 1 & 2.6 & 5 & 2.6 \\
\hline Chronic neonatal lung disease & 2 & 1.3 & 0 & 0.0 & 2 & 1.0 \\
\hline Total & 16 & 10.5 & 5 & 12.8 & 21 & 10.9 \\
\hline \multicolumn{7}{|l|}{ 4. Infection } \\
\hline Other & 1 & 0.7 & 0 & 0.0 & 1 & 0.5 \\
\hline Congenital bacterial & 2 & 1.3 & 1 & 2.6 & 3 & 1.6 \\
\hline Acquired bacterial & 5 & 3.3 & 1 & 2.6 & 6 & 3.1 \\
\hline Fungal & 1 & 0.7 & 0 & 0.0 & 1 & 0.5 \\
\hline Total & 9 & 5.9 & 2 & 5.1 & 11 & 5.7 \\
\hline \multicolumn{7}{|l|}{ 5. Neurological } \\
\hline Other & 1 & 0.7 & 0 & 0.0 & 1 & 0.5 \\
\hline Hypoxic ischaemic encephalopathy- & & & & & & \\
\hline perinatal asphyxia & 1 & 0.7 & 12 & 30.8 & 13 & 6.8 \\
\hline Intracranial haemorrhage & 10 & 6.5 & 0 & 0.0 & 10 & 5.2 \\
\hline Total & 12 & 7.8 & 12 & 30.8 & 24 & 12.5 \\
\hline \multicolumn{7}{|l|}{ 6. Gastrointestinal } \\
\hline Other & 0 & 0.0 & 1 & 2.6 & 1 & 0.5 \\
\hline Necrotising enterocolitis & 5 & 3.3 & 0 & 0.0 & 5 & 2.6 \\
\hline Total & 5 & 3.3 & 1 & 2.6 & 6 & 3.1 \\
\hline \multicolumn{7}{|l|}{ 7. Other } \\
\hline SIDS & 0 & 0.0 & 1 & 2.6 & 1 & 0.5 \\
\hline Other & 2 & 1.3 & 3 & 7.7 & 5 & 2.6 \\
\hline Undetermined/Unknown & 0 & 0.0 & 1 & 2.6 & 1 & 0.5 \\
\hline Total & 2 & 1.3 & 5 & 12.8 & 7 & 3.6 \\
\hline TOTAL & 153 & 100.0 & 39 & 100.0 & 192 & 100.0 \\
\hline
\end{tabular}

Source: NSW Maternal and Perinatal Committee, NSW Department of Health. 


\section{SURVEY ON THE MANAGEMENT OF STILLBIRTHS IN NSW HOSPITALS}

\section{Introduction}

Stillbirths account for approximately two-thirds of all perinatal deaths in NSW. In response, the NSW Department of Health and the NSW Maternal and Perinatal Committee recommended that a review be carried out to inform best practice on the management of stillbirths.

A Stillbirth Reference Group was convened in early 2003, comprising members from: the NSW Maternal and Perinatal Committee; Department of Health staff representing the Centre for Mental Health, the Nursing and Midwifery Office, and Statewide Services Development Branch; SIDS and Kids NSW; the NSW Pregnancy and Newborn Services Network and the NSW Genetic Services Advisory Committee. The Reference Group recommended that a statewide survey of Area Health Services be carried out to examine current practices in the management of stillbirths, and to determine the extent of the alignment of these practices with Department of Health guidelines. ${ }^{1}$

\section{Method}

In 2003 a self-administered questionnaire was distributed to all public hospitals in NSW which reported a birth in 2002. Questions were included on the following:

- hospital policies and procedures for the management of stillbirths;

- clinical investigations routinely performed on mothers following a stillbirth;

- clinical investigations offered to parents following a stillbirth;

- expected timeframe for parents to obtain post-mortem results; and

- access to counselling services for parents of a stillborn infant.

Information from returned questionnaires were entered into an electronic spreadsheet and descriptive statistics were produced.

\section{TABLE 130}

\section{HOSPITALS ROUTINELY PERFORMING MATERNAL INVESTIGATIONS}

\begin{tabular}{|llr|}
\hline Maternal investigations & \multicolumn{3}{c|}{ Hospitals } \\
& No. & $\%$ \\
\hline Full blood count & 63 & 84.0 \\
Blood group and antibody screen & 63 & 84.0 \\
Infection screen for TORCH organisms and syphilis & 59 & 78.7 \\
Gestational diabetes & 58 & 77.3 \\
Kleihauer count & 56 & 74.7 \\
Assessment of anti-nuclear and & 52 & 69.3 \\
$\quad$ anti-phospholipid antibodies & 47 & 62.7 \\
Haemoglobin electrophoresis & 40 & 53.3 \\
Maternal vaginal swab & 36 & 48.0 \\
Swab from the chorionic surface of the placenta & & \multicolumn{3}{c|}{} \\
\end{tabular}

\section{Results}

Of the 107 public hospitals in NSW that reported at least one birth, 75 responded to the survey; an overall response rate of 70 per cent. At least one hospital in each of the then 17 Area Health Services completed the survey.

Policies and procedures that accorded with NSW Department of Health guidelines for the investigation of stillbirths ${ }^{1}$ were in place in 63 of the 75 respondent hospitals. Policies were being updated or reviewed in a further 4 hospitals.

Thirty-one percent of hospitals reported that all nine maternal investigations listed in Table 130 were routinely requested. The most frequently ordered maternal investigations were: full blood count, blood group and antibody screen. Seventy-seven percent of hospitals routinely sent the placenta for histopathology following a stillbirth.

Post-mortem investigations were routinely offered to parents following a stillbirth in 85 per cent of hospitals. Almost half of the respondents identified the same hospital as performing the placental histopathology and the postmortem examination of the stillborn infant. Clinical investigations routinely performed on a stillborn infant are listed in Table 131, with fetal karyotype and a total body X-ray routinely carried out by 75 per cent and 56 per cent of hospitals respectively, for stillborn infants with congenital abnormalities.

All hospitals reported that post-mortem examinations were performed at no charge to parents. The reported timeframe within which parents could expect to obtain the final post-mortem examination result ranged from six weeks to six months.

Almost all hospitals reported that families had the opportunity to see and hold their stillborn baby and to take photographs. Ninety-five per cent of hospitals reported that parents were able to access counselling and bereavement services following a stillbirth.

\section{TABLE 131}

HOSPITALS ROUTINELY PERFORMING FETAL CLINICAL INVESTIGATIONS

\begin{tabular}{|lcc|}
\hline Maternal investigations & \multicolumn{2}{l}{ Hospitals* $^{*}$} \\
& No. & $\%$ \\
\hline Description of clinical appearance & 61 & 81.3 \\
Fetal karyotype & 56 & 74.7 \\
Total body X-ray (fetogram) & 42 & 56.0 \\
Anatomical photographs & 35 & 46.7 \\
Fetal blood cultures & 25 & 33.3 \\
\hline
\end{tabular}

* Total hospitals $n=75$.

* Total hospitals $n=75$. 


\section{Discussion}

A post-mortem examination and maternal investigations can provide valuable information to health professionals on the cause of death of a stillborn baby. These investigations may assist parents by providing information that will enable informed decision making for the planning of future pregnancies.

This statewide survey of NSW hospitals provided an overview of current practices on the management of stillbirths. A key finding of the survey was that, despite 85 per cent of hospitals routinely offering to parents a postmortem investigation of a stillborn infant, the perinatal post-mortem rate remains below 40 per cent.

One way to improve post-mortem rates is by ensuring that health professionals are well-informed, and clearly and sensitively discuss the post-mortem process with parents. In early 2004, the NSW Health Department issued Circular 2004/1 entitled Use and retention of human tissue including organ donation, post-mortem examination and coronial matters. This policy was developed in response to legislative changes and recommendations from major reports and enquiries, including the Walker Inquiry ${ }^{1}$ and the National Code of Ethical Autopsy Practice. ${ }^{2}$ The National Code of Ethical Autopsy Practice advises that institutions have a responsibility to ensure that a specially trained staff member engages with the bereaved family and provides clear and factual information. ${ }^{3}$ The NSW Department of Health policy describes this role as the Post-Mortem Coordinator. It is expected that the appointment of a Post-Mortem Coordinator in hospitals that provide non-coronial postmortems will ensure parents receive information, support and assistance with the post-mortem process.

To further improve the management of stillbirths, there is a need to ensure that health professionals are aware of the need for routine clinical investigations. The survey found that all nine maternal clinical investigations were reported to be routinely performed in approximately one third of hospitals. However, these results also reflect that the series of maternal investigations outlined in Table 1 may not be clinically appropriate for all cases of stillbirths or may be undertaken at a later time. There is scope to improve the uptake of maternal investigations where it is clinically indicated, particularly when the offer of a post-mortem examination of the stillborn baby has been declined. Without such investigations, it is more difficult to advise parents about the cause of death or identify risks which may affect the outcome of future pregnancies. ${ }^{4}$

Overall, respondents acknowledged the need to provide holistic care in the management of a stillbirth, and also to ensure open, honest and sensitive discussion of the post-mortem process.

\section{References}

1. NSW Department of Health. Circular 97/107 Guidelines for investigation of a stillbirth.

2. Walker B. Inquiry into matters arising from the postmortem and anatomical examination practices of the Institute of Forensic Medicine. Sydney: NSW Department of Health, 2001.

3. Australian Health Ministers' Advisory Council Subcommittee on Autopsy Practice. The National Code of Ethical Autopsy Practice. Adelaide: South Australian Department of Human Services, 2002.

4. Maternal and Child Health Research Consortium. Confidential Enquiry into Stillbirths and Deaths in Infancy 8th Annual Report. London: Maternal and Child Health Research Consortium, 2001. 